\title{
OPINION
}

\section{Next-generation community genetics for low- and middle-income countries}

\author{
Stephen F Kingsmore*, John D Lantos, Darrell L Dinwiddie, Neil A Miller, Sarah E Soden, Emily G Farrow \\ and Carol J Saunders
}

\begin{abstract}
A recent report by the World Health Organization calls for implementation of community genetics programs in low- and middle-income countries (LMICs). Their focus is prevention of congenital disorders and genetic diseases at the population level, in addition to providing genetics services, including diagnosis and counseling. The proposed strategies include both newborn screening and population screening for carrier detection, in addition to lowering the incidence of congenital disorders and genetic diseases through the removal of environmental factors. In this article, we consider the potential impact of such testing on global health and highlight the near-term relevance of next-generation sequencing (NGS) and bioinformatic approaches to their implementation. Key attributes of NGS for community genetics programs are homogeneous approach, high multiplexing of diseases and samples, as well as rapidly falling costs of new technologies. In the near future, we estimate that appropriate use of population-specific test panels could cost as little as $\$ 10$ for 10 Mendelian disorders and could have a major impact on diseases that currently affect $2 \%$ of children worldwide. However, the successful deployment of this technological innovation in LMICs will require high value for human life, thoughtful implementation, and autonomy of individual decisions, supported by appropriate genetic counseling and community education.
\end{abstract}

Keywords Community genetics, low income countries, Mendelian disease, multiplexing, newborn screening, next-generation sequencing, preconception carrier testing.
*Correspondence: sfkingsmore@cmh.edu

Center for Pediatric Genomic Medicine, Children's Mercy Hospitals and Clinics, 2401 Gilham Road, Kansas City, MO 64108, USA

\section{The global challenge of genetic diseases}

The World Health Organization (WHO) recently recommended the implementation of community genetics programs in low- and middle-income countries (LMICs, as defined by the World Bank) [1]. The focus of these recommendations is the prevention of congenital disorders and genetic diseases at the population level, in addition to providing genetics services, including diagnosis and counseling, for individuals and families. The proposed strategies include newborn screening for preventable disorders, such as congenital hypothyroidism and phenylketonuria where immediate intervention can prevent mental retardation, and population screening for carrier detection for common recessive conditions, such as sickle cell anemia and alpha-thalassemia. In addition to such screening programs, the WHO also calls for programs to prevent congenital disorders and genetic diseases through the removal of environmental factors.

Severe congenital disorders cause a great deal of morbidity and mortality throughout the world. The global birth prevalence of congenital disorders that are lethal or cause lifelong impairment is estimated to be $5 \%$ to $7 \%[2,3]$. About half of these are thought to be attributable to Mendelian (single gene) disorders. The true birth prevalence of many disorders in LMICs with poor surveillance is not known [3]. Most Mendelian disorders are rare; however, in aggregate they affect millions of people globally. As the number of people affected by any one specific rare disease is relatively small, a host of challenges complicate the development of effective drugs and medical devices to prevent, diagnose, treat or cure these conditions. These include small patient populations of affected patients for clinical testing and diminished financial incentives. Thus, addressing the global health challenge posed by such diseases will call for different strategies to those that have been used for diseases that are more prevalent.

The Institute of Medicine recently released a report calling for the creation of a far-reaching national US strategy to accelerate drug development by sharing ideas and resources to improve research and development for rare diseases [4]. Implementation of strategies to identify 
and treat such diseases in LMICs requires careful justification. However, LMICs are economically the least able to cope with the lifelong burden caused by childhood genetic diseases, especially if those diseases are undiagnosed or if treatment is experimental or expensive.

The design of screening programs is made complicated by the wide variation in the prevalence of individual Mendelian diseases in different regions, reflecting the rich tapestry of population substructure woven over thousands of years, overlaid with various intraspecific evolutionary pressures. For example, glucose-6-phosphate dehydrogenase (G6PD) deficiency and sickle cell disease (also known as hemoglobin S) alleles are under intense positive selection in malarial regions. Thus, 15 million Africans are affected by sickle cell anemia and the birth incidence in Nigeria and Sierra Leone is around $2 \%$ [5]. Likewise, thalassemias affect up to $1 \%$ of births across large parts of southern Europe and Asia [6]. In contrast, cystic fibrosis is prevalent in countries with populations largely of north European ancestry (Table 1). A practical consequence of the marked heterogeneity in allele frequency is that testing priorities vary widely by region and ethnic group. The disease targets of community genetics programs will differ correspondingly. In addition to wide regional differences, the frequencies of individual risk alleles can differ markedly between geographically contiguous but reproductively isolated groups. A dramatic example is G6PD deficiency in Tanzania, where prevalence in lowland and highland populations ( $11.3 \%$ and $4.4 \%$, respectively) mirrors that of malaria [7]. Thus, genetic testing priorities should include pretest probabilities in subpopulations rather than geographic averages, an onerous requirement for genetics programs in LMICS. However, demographic transition is occurring in many LMICs, increasing the importance of genetic disease.

This article will discuss how inexpensive multiplexed next-generation sequencing (NGS)-based testing could be employed for carrier screening, newborn screening and diagnostic testing in LMICs. Accompanied by appropriate genetic counseling and community education, this approach could reduce the number of affected individuals burdened by common genetic diseases such as hemoglobinopathies. We suggest a model for a pilot program and discuss potential obstacles.

\section{Next-generation approaches for community genetic testing}

There are three types of programs in which new genetic screening technologies could be used in LMICs: carrier testing, newborn screening and diagnostic testing. In this section, we will discuss the challenges and potential impact of next-generation approaches for each of these programs.
Table 1. Ten prevalent Mendelian disorders and regions with highest birth prevalence

\begin{tabular}{|c|c|c|c|}
\hline Disease & Inheritance & $\begin{array}{l}\text { OMIM } \\
\text { no. }\end{array}$ & Highest incidence \\
\hline Beta-thalassemia & $A R$ & 613985 & 1:5, Maldives [45] \\
\hline Cystic fibrosis & $A R$ & 219700 & $1: 2,500$, Ireland [46] \\
\hline Phenylketonuria & AR & 261600 & 1:2,600, Turkey [47] \\
\hline Sickle cell disease & $A R$ & 603903 & 1:5, Baamba, Uganda [48] \\
\hline Spinal muscular atrophy & $A R$ & 253300 & 1:5,600, Slovakia [49] \\
\hline $\begin{array}{l}\text { Duchenne muscular } \\
\text { dystrophy }\end{array}$ & X-linked & 310200 & $1: 3,500$, USA [50] \\
\hline Fragile $X$ syndrome & X-linked & 300624 & $\begin{array}{l}\text { 1:3,300 (full mutation, male } \\
\text { and female), USA [51] }\end{array}$ \\
\hline G6PD deficiency & X-linked & 305900 & 1:8, Basra, Iraq [52] \\
\hline Hemophilia A & X-linked & 306700 & 1:5,000, worldwide [53] \\
\hline Tay-Sachs disease & X-linked & 272800 & $\begin{array}{l}\text { 1:3,000 (previously, Ashkenazi } \\
\text { Jews) [13] }\end{array}$ \\
\hline
\end{tabular}

AR, autosomal recessive; G6PD, G6PD, glucose-6-phosphate dehydrogenase; OMIM, Online Mendelian Inheritance in Man [54].

\section{Carrier testing}

The WHO recommends carrier testing for common autosomal recessive diseases such as hemoglobinopathies [1]. Unlike newborn screening, which may benefit affected individuals by allowing early, ongoing treatment, the goal of carrier testing programs is to inform people of their risk for genetic disease in order to help them make decisions about marriage and reproduction. Critically, carrier testing is not limited to diseases for which effective treatments are available and has minimal ongoing economic cost. Thus, it is well-suited for community deployment in LMICs, where individuals are identified by screening, ideally before marriage or pregnancy. The incidence of specific recessive diseases can be reduced in future generations via broad community adoption of preconception screening, health education and genetic counseling.

Ethically sound genetic testing must meet several core principles in order to do more good than harm. Individual autonomy must be respected; individuals should be given adequate information to make decisions for themselves about whether or not to undergo testing. There must be high standards of confidentiality and protection against discrimination. These can be highly complex and controversial. In some cultures, individual autonomy is not an important value. Instead, a tribal chief or village headman makes decisions for the community. Also, many countries do not have systems to protect against discrimination. Programs of carrier screening have also led to discrimination against carriers of autosomal recessive conditions. Carriers of thalassemia identified through screening programs in West Bengal, India, were subsequently deemed unfit for marriage, and 
this had significant ramifications for women [8]. Furthermore, vulnerable populations differ between societies; gender and ethnicity, as examples, often affect the status of a person in LMICs. Thus, the development of carrier testing programs requires close collaboration with local institutions, leaders, individuals and healthcare providers. They should also be informed by previous experience with carrier testing for individual diseases in LMICs.

Despite these ethical concerns, several LMICs have instituted successful carrier screening programs. Iran, Cyprus and Turkey currently have mandatory premarital screening programs for thalassemia, while in other LMICs, such as Egypt and the Maldives, screening is voluntary [9-11].

The effectiveness and ethical acceptability of communitybased carrier screening varies according to screening strategy, the ethos in the community, and the willingness of individuals and couples to alter their reproductive decisions. Perhaps the best-known example of effective population carrier screening is that of Tay-Sachs disease in the Ashkenazi Jewish population in the USA. This program resulted in a reduction of more than $90 \%$ in incidence of disease $[12,13]$. This voluntary screening program relies on the identification of carriers by reduced hexosaminidase A activity in leukocytes or direct mutation testing, prenatal testing for pregnancies at risk, and termination of affected pregnancies [12,13]. For some religious groups, such as Orthodox Jews, another option was added. In this community, arranged marriages are common. This allowed a program known as Chevra Dor Yeshorim to be established that provided anonymous premarital testing with the information given to the rabbi. The rabbi could then alter the selection of a marriage partner utilizing this information. [14]. Since most couples in this population marry by the age of 20 , screening is primarily carried out in high school. Between 1982 and 2006, over 200,000 individuals were tested for Tay-Sachs carrier status, averting over 800 arranged marriages between carriers [15]. The vast majority of 'incompatible' couples elected not to marry following intensive counseling [14]. This model may also be feasible for some LMICs, particularly those where arranged marriage is common.

Premarital screening for thalassemia and sickle cell disease followed by genetic counseling has been implemented in Bahrain, Iran, Cyprus, Saudi Arabia and Jordan $[16,17]$. Although many Saudi couples opt to go through with the marriage despite receiving an 'incompatibility certificate', voluntary cancellation of marriage proposals among at-risk couples increased more than fivefold between 2004 and 2009 [18]. One survey found that the top factor that influenced the decision not to marry was having knowledge of a family history of the disease, while reasons couples cited for proceeding with marriage were that wedding plans could not be canceled and fear of social stigma [9].

Strategies such as those used in Bahrain, Saudi Arabia and Jordan, as well as those used in Chevra Dor Yeshorim, along with extensive counseling, might be utilized in the development of targeted carrier testing programs for LMICs. While comprehensive carrier testing for all recessive diseases is impractical, the aforementioned population screening programs provide a model for successful targeted testing. Thus, a suggested model for next-generation carrier testing in LMICs is premarital, on a population-by-population basis, tailored to recessive diseases with an incidence greater than, for example, $1: 10,000$.

While carrier screening programs in LMICs could target diseases common to specific countries or populations, a confounding factor for some areas is consanguinity, which increases the risk for offspring with common genetic diseases as well as rare recessive disorders that would not likely be screened. Though taboo in much of the western world, consanguineous marriage (usually considered to be between second cousins or closer) is traditional and respected in most communities of North Africa, the Middle East and western Asia, with intrafamilial unions accounting for $20 \%$ to $50 \%$ or more of marriages in some populations [19]. The prevalence of congenital anomalies in the offspring of first cousin marriages is estimated to be $1.7 \%$ to $2.8 \%$ higher than the average background risk of 4\% [20], and this is attributed mostly to autosomal recessive diseases [19]. Assuming an increased risk of $2 \%$ above the background risk, $8 \%$ of first cousin consanguineous couples would have a risk of $25 \%$ or more of having a child with an autosomal recessive disorder. The remaining $92 \%$ of first cousin consanguineous marriages would not have an increased risk over that of the general population [19]. The prevalence of consanguinity varies widely according to geography, ethnicity, religion and culture; thus, the potential benefit of community carrier screening programs varies widely among tribes, regions and countries. In areas where consanguinity is common and the prevalence of autosomal recessive diseases is higher, carrier testing programs are likely to be more cost-effective.

In industrialized countries, such as the USA, where population-based carrier screening for individual disorders is widely accepted, the development of carrier screening utilizing NGS has focused on the capacity of the test to screen for recessive conditions [21]. In this regard, the tests will screen for more than 400 recessive conditions that affect multiple ethnicities and populations. To date, the implementation of this testing has been limited by cost and analysis time. However, this type of NGS carrier screening is currently not appropriate for LMICs for multiple reasons, including a lack of 
infrastructure to disseminate the test results and the relative rarity of the conditions that are included.

\section{Newborn screening}

Newborn screening is indicated for the subset of testable diseases that benefit from early treatment, such as phenylketonurea, galactosemia and cystic fibrosis [22]. In the USA, approximately 4 million neonates are screened annually for at least 29 largely inherited diseases using dried blood spots on Guthrie cards [23]. As a result, around 12,500 diagnoses are made, at a test cost of approximately $\$ 1$ per disease per newborn [24]. This is considered cost-effective, but the effectiveness of newborn screening programs depends upon the availability of follow-up and treatment $[22,24]$. The cost and costeffectiveness of screening, diagnosis and treatment will be variable in LMICs. For example, newborn screening for congenital hypothyroidism, which is detected in 1:2,000 US tests and can be inexpensively treated with oral thyroxine, is a practical target for many LMICs. Indeed, newborn screening for congenital hypothyroidism is already utilized in some Middle East countries $[25,26]$. In contrast, screening for lysosomal storage disorders, which are treated with prohibitively expensive recombinant enzyme replacement therapies, would be impractical in LMICs. Diseases such as congenital adrenal hyperplasia, which is treated with glucocorticoids, might be somewhere between hypothyroidism and lysosomal storage diseases in terms of cost-effectiveness for use in LMICs.

Most newborn screening programs do not use NGS. At this time, conventional tests for several diseases are currently less expensive and/or more practicable than NGS. Immunoassays for hypothyroidism, for example, identify both genetic and environmental causes. Mass spectrometry allows simultaneous testing for many biochemical disorders, such as phenylketonuria and galactosemia. Hemoglobin electrophoresis identifies a wide variety of hemoglobinopathies. Nevertheless, NGS uniquely offers a homogeneous format for the large majority of Mendelian diseases and costs that are decreasing by approximately tenfold per year [27]. It is possible that, in the future, advances in testing technology will lower the cost of NGS to the point where its use becomes more cost-effective than currently available testing methodologies.

\section{Diagnostic testing}

Molecular diagnostic testing is currently prohibitively expensive for many patients, even in high-income countries. Many diseases exhibit locus and/or clinical heterogeneity, engendering lengthy and costly differential diagnostic odysseys. Thus, many patients who have symptoms suggestive of a genetic disease may never receive a molecular diagnosis, even after undergoing genetic testing worth thousands of dollars. Part of the problem is that current testing strategies dictate testing for specific diseases, and each test is costly and time consuming. Such testing can take months or years, delaying timely intervention or counseling; a second affected child may be born before the first is diagnosed with the disorder. NGS is beginning to change this, with several commercial laboratories currently offering large panels of NGS-based clinical tests, and more comprehensive and cost-effective testing is on the horizon [21].

\section{Implementing next-generation genetic testing in LMICs}

Currently, the infrastructure to translate molecular understanding of disease inheritance into medically actionable information for individuals and families is remarkably uneven. While clinical tests are available for 2,210 diseases, they are performed by 603 laboratories registered on the GeneTests website, only 256 of which are outside the USA [28]. Of the international laboratories registered, none are located in low-income countries, and only 20 are in middle-income countries [28]. It should be noted that, in part, this may reflect uneven registration of laboratories. NGS and bioinformatic approaches have the potential to transform this situation by enabling DNA sequence analysis of unprecedented scale and economy $[21,29]$, with a current ability to generate 600 billion nucleotides per instrument run. This technical capacity translates to an ability to test approximately 200 individuals for up to 600 Mendelian diseases $[21,30]$. For community genetics programs in LMICs, we suggest that this sequencing capacity could be reconfigured to allow testing of approximately 1,500 individuals for up to 10 diseases. Such multiplexing of samples and tests is feasible with NGS and molecular barcoding, enabling the simultaneous sequencing of multiple combined samples to provide maximum costeffectiveness [2]. We estimate that today such testing, if performed to clinical grade in a low- or middle-income country with self-sustaining economics, could currently cost approximately $\$ 23$ per individual (Box 1). Since the cost of NGS is decreasing approximately 10 -fold every 18 months, population-specific test panels could cost as little as $\$ 10$ for 10 Mendelian disorders in the near future. While currently still out of reach for population testing in LMICs, it should be noted that genome sequencing costs are likely to continue to decrease for the foreseeable future $[2,29,30]$. Thus, an additional 30 -fold decrease in cost is highly likely within several years [27]. Dried blood spots offer an attractive solution for sample acquisition in LMICs, given the cost, ease of collection and shipping, providing a means to regionalize testing in centers similar to current reference laboratories. Storage and access mechanisms for electronic results would also be required 


\section{Box 1. Estimated cost and assumptions for multiplexed next-generation genetic testing \\ 2 to 10 Mendelian disease genes screened \\ 90,000 samples per year per 'module' \\ \$22.88 fully-loaded test cost per sample \\ $\$ 12.28$ consumables per sample: \\ Next-generation sequencing at $300 \mathrm{~Gb}$ per 5 days \\ Target selection by multiplexed, barcoded PCR with generic oligonucleotides \\ Library preparation with generic oligonucleotides \\ $0.1 \mathrm{~Gb}$ sequence generated per sample}

\section{Approximately $\$ 1.2$ million capital equipment:}

Assumes 4 year life

Includes service contracts, overhead costs

Capital equipment largely automates sample processing

Significant quality assurance/quality control procedures

Approximately $\mathbf{\$ 5 8 0 , 0 0 0 ~ s a l a r i e s / b e n e f i t s ~ p e r ~ y e a r ' : ~}$

11 full-time personnel; rates adjusted to LMIC economics

IT/bioinformatics/software engineer: 2 personnel

Clinical interpretation/reporting: 4 personnel

$\mathrm{IT}$, software and bioinformatics tools largely automate variant interpretation

Assumes no royalty payments on gene patents

'Does not account for education and training costs, particularly for community physicians, geneticists and genetic counselors

in order to implement NGS effectively; this contrasts with current, predominantly paper records in LMICs. This could be part of a broad effort to implement electronic medical records, which can help to facilitate improved care, efficiency and cost-effectiveness. Alternatively, these approaches could be limited to regionalized data generation centers, with existing infrastructure for reporting of results.

One objection that is often raised to such testing is that LMICs cannot afford it. However, there is a policy paradox embedded in this assumption. It does not consider the cost to the countries of the diseases themselves, only the cost of testing. Conceptually, the countries that would benefit the most from NGS testing are those with the lowest income, little or no currently available screening, and the highest rates of consanguinity, fertility and infant mortality. In those countries, genetic disease is common and expensive, and testing would likely be the most cost-effective precisely because the prevalence of disease is high.

One general region of interest would be Middle East countries, many of which meet all of those specifications, in addition to having much higher rates of birth defects than Europe, North America and Australia (69.9/1,000 compared with 52.1/1,000 live births) [3]. In addition, a realistic model for piloting implementation of NGS testing would require a level of genetics literacy and resources not yet available for the lowest income countries.

Imagine, for example, a test that costs approximately \$23 and that can detect the 10 most prevalent Mendelian disorders. Imagine, further, that such a test might be offered in a middle-income country such as Lebanon, which currently has a premarital screening program for thalassemia along with existing infrastructure and sufficient resources to carry out post-testing follow-up and counseling [31]. In Lebanon, premarital screening for thalassemia is well accepted. The program there has decreased the number of new cases of thalassemia by about $75 \%$ since 1994, with three new cases identified in 2006. Prenatal diagnosis is also performed when both parents are known to be carriers of the disease. An average of 13 amniocentesis tests have been performed per year since 2000 and have resulted in the identification of around $50 \%$ carriers, $25 \%$ patients with thalassemia, and $25 \%$ disease-free neonates [32]. With a population of 4 million and a birth rate of 70,000, the expanded premarital screening of 10 diseases could be quite costeffective in the population. Furthermore, in Lebanon, both arranged marriages and consanguineous marriages are common. It is estimated that $30 \%$ of Muslims and $17 \%$ of Christians enter into consanguineous relationships [33]. This leads to a high prevalence and high burden of disease in Lebanon, with carrier rates of $2 \%$ to $4 \%$ for alpha-thalassemia, $2 \%$ to $4 \%$ for beta-thalassemia [34], and $0.3 \%$ to $30 \%$ for sickle cell anemia in Arab countries [32]. It is likely that other autosomal recessive conditions also occur at higher rates than in other countries. Therefore, one could consider adding spinal muscular atrophy (general population carrier frequency of 1 in 25 to 1 in 50 in some Arab countries [33]) and cystic fibrosis (general population carrier frequency of 1 in 25 to 1 in 60 in some Arab countries $[33,35]$ ) to the current screening panel (Table 2). The collective cost of treating these five disorders is substantial. For example, mean total medical costs for patients with sickle cell anemia and thalassemia were $\$ 59,233$ per year in the USA [36] and $\$ 7,000$ per year in Israel [37]. In the USA, the average total cost of Mendelian disorders has been estimated to be the equivalent of approximately $\$ 360$ per birth [38]. Other factors in addition to health economic consequences should also be considered in justification of screening programs. These include the Wilson and 
Table 2. Potential targets for premarital carrier screening in Arabic LMICs

\begin{tabular}{lccl}
\hline Disease & Inheritance & $\begin{array}{c}\text { OMIM } \\
\text { no. }\end{array}$ & $\begin{array}{l}\text { Carrier frequency in Arab } \\
\text { populations }[35,55]\end{array}$ \\
\hline Sickle cell disease & AR & 603903 & $0.3 \%$ to $30 \%$ \\
Beta-thalassemia & AR & 613985 & $2 \%$ to $7 \%$ \\
Alpha-thalassemia & AR & 604131 & $2 \%$ to $50 \%$ \\
Cystic fibrosis & AR & 219700 & $1 / 25$ to $1 / 50$ \\
Spinal muscular atrophy & AR & 253300 & $1 / 25$ to $1 / 60$
\end{tabular}

AR, autosomal recessive; LMICs, low- and middle-income countries; OMIM, Online Mendelian Inheritance in Man [54].

Jungner criteria [39] (Box 2) and factors identified in the 2011 report by the UK Human Genetics Commission [40].

It is very difficult to provide a prospective estimation of the cost-effectiveness of reducing the incidence of approximately 10 relatively common inherited childhood diseases by around $90 \%$, as predicted by success in other premarital screening programs. The remaining five potential targets are likely to vary by population group (Tables 1 and 2). As noted above, while the current costs of testing can be determined precisely, the full cost of a national community genetics infrastructure cannot. Furthermore, cost-effectiveness of the addition of a test panel is largely driven by existing community genetics infrastructure commitments and local cost of treatment of affected individuals. Nevertheless, \$23 per test is certainly within the realm for implementation of a pilot program of next-generation community genetics in a country such as Lebanon. Successful implementation would serve as a template for other LMICs as sequencing costs become more affordable and as cost-effectiveness data become available.

\section{Conclusions and future directions}

Newborn screening for preventable childhood disorders and population screening for carrier detection for common recessive diseases, when combined with genetic counseling and medical treatments, have been shown to be cost-effective and beneficial to patients and families in many countries. Given this experience, the WHO recently recommended extension of such strategies in LMICs. Hitherto, the principal obstacles to such testing of populations in LMICs have been test cost and inadequate community genetics and medical infrastructure to administer tests, interpret results and provide appropriate counseling and medical treatments. NGS and bioinformatics have made possible highly multiplexed molecular genetic testing, in terms of both diseases tested and sample batching. In the USA, this is allowing a dramatic broadening of genetic test menus and decreasing costs of testing. In LMICs, these

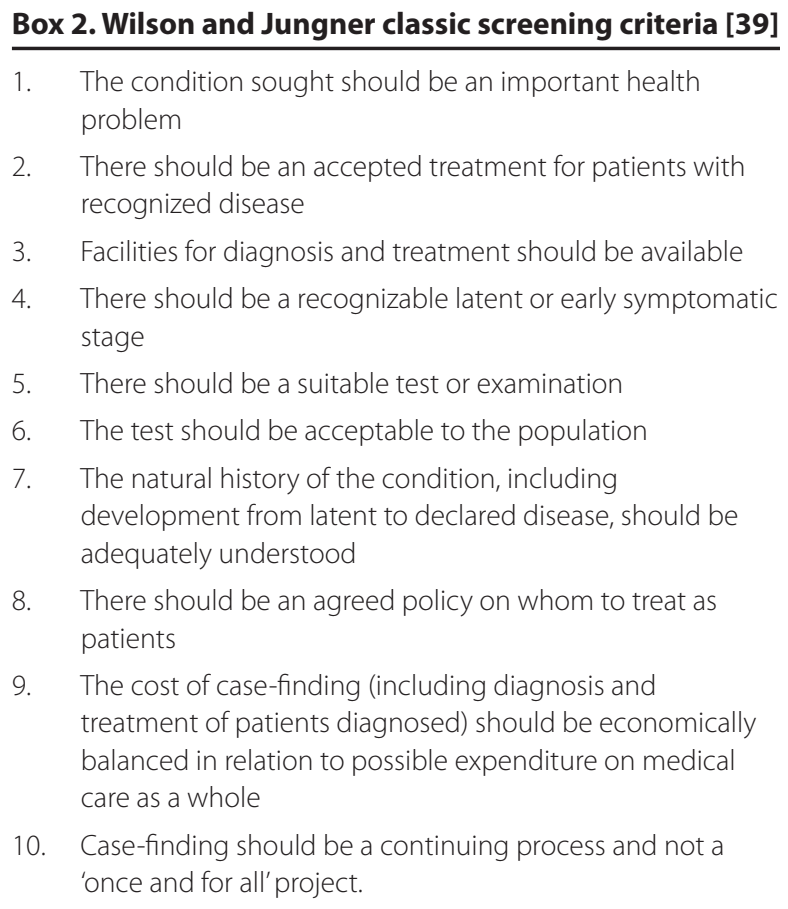

1. The condition sought should be an important health problem

2. There should be an accepted treatment for patients with recognized disease

3. Facilities for diagnosis and treatment should be available

4. There should be a recognizable latent or early symptomatic stage

5. There should be a suitable test or examination

6. The test should be acceptable to the population

7. The natural history of the condition, including development from latent to declared disease, should be adequately understood

8. There should be an agreed policy on whom to treat as patients

9. The cost of case-finding (including diagnosis and treatment of patients diagnosed) should be economically balanced in relation to possible expenditure on medical care as a whole

10. Case-finding should be a continuing process and not a 'once and for all' project.

technologies are poised to remove the test cost barrier to implementation of community genetics testing. However, the scope, content and intent of such testing requires careful consideration.

Disease allele frequencies vary widely among and within LMICs, as do ethical, legal, social and economic realities. Principal challenges to community genetics in LMICs are educating the population, creating an infrastructure of genetics professionals capable of offering appropriate counseling and follow-up, and appropriate consideration of core ethical principles in a world where there is not universal agreement about human rights.

Finally, it should be noted that the proportion of common disease burden attributed to Mendelian inheritance is being re-assessed in light of the common disease-rare variant hypothesis $[41,42]$, which states that a proportion of common disease burden is attributable to uncommon, highly penetrant, recessive mutations. There is evidence for this hypothesis in autism, schizophrenia, bipolar disorder, Alzheimer's disease and early-onset intellectual disability (reviewed in [43]). Around 10\% of childhood intellectual disability, the incidence of which exceeds $2 \%$ worldwide, is inherited in an X-linked recessive manner, with over 100 causal genes (reviewed in [43]). Recently, over 50 additional autosomal recessive loci have been implicated in intellectual disability [44]. Thus, the proportion of common diseases attributable to single genes is likely to continue to increase. The relevance for LMICs is that the potential scope of community genetics testing is likely to increase as subsets 
of common, 'complex' disorders are also shown to be Mendelian.

In summary, the WHO recommendations that genetic screening programs be developed in LMICs are often dismissed as unrealistic from the perspective of costeffectiveness and resource allocation. However, a closer look at the rapidly falling costs of genetic testing, the high prevalence of genetic disease in many countries, the cost savings that could be achieved by effective screening programs, and the acceptability of such programs in many countries, leads us to conclude that such programs are feasible, ethically defensible and potentially costeffective. It may be time to rethink our approach to rare genetic diseases throughout the world [4]. NGS provides the tools that might make such community genetics programs more possible in LMICs.

\section{Abbreviations}

G6PD, glucose-6-phosphate dehydrogenase; LMICs, low- and middle-income countries; NGS, next-generation sequencing; WHO, World Health Organization.

\section{Competing interests}

The authors declare that they have no competing interests.

\section{Acknowledgements}

This work was inspired by the Beyond Batten Disease Foundation. Thanks to Steve Leeder, Mike Artman and Michael Begleiter for helpful discussions, and to Amanda Bierstine for administrative assistance. A Deo mirificatio, ab amicis auxilium.

Published: 29 March 2012

\section{References}

1. World Health Organization: Community Genetics Services: Report of a WHO Consultation on Community Genetics in Low-and Middle-Income Countries. Geneva: 2011

2. Alwan A, Modell B: Recommendations for introducing genetics services in developing countries. Nat Rev Genet 2003, 4:61-68.

3. Christianson A, Howson CP, Modell B: March of Dimes Global Report on Birth Defects: The Hidden Toll of Dying and Disabled Children. White Plains, NY: March of Dimes Birth Defects Foundation; 2006. [http://www.marchofdimes.com/ downloads/Birth_Defects_Report-PF.pdf]

4. Institute of Medicine: Rare Diseases and Orphan Products: Accelerating Research and Development. Washington; 2010. [http://www.iom.edu/Reports/2010/ Rare-Diseases-and-Orphan-Products-Accelerating-Research-andDevelopment.aspx]

5. Aliyu ZY, Kato GJ, Taylor J 6th, Babadoko A, Mamman Al, Gordeuk VR, Gladwin MT: Sickle cell disease and pulmonary hypertension in Africa: a global perspective and review of epidemiology, pathophysiology, and management. Am J Hematol 2008, 83:63-70.

6. Modell B, Darlison M: Global epidemiology of haemoglobin disorders and derived service indicators. Bull World Health Organ 2008, 86:480-487.

7. Segeja MD, Mmbando BP, Kamugisha ML, Akida JA, Savaeli ZX, Minja DT, Msangeni HA, Lemnge MM: Prevalence of glucose-6-phosphate dehydrogenase deficiency and haemoglobin $\mathrm{S}$ in high and moderate malaria transmission areas of Muheza, north-eastern Tanzania. Tanzan $J$ Health Res 2008, 10:9-13.

8. Chattopadhyay S: 'Rakter dosh' - corrupting blood: The challenges of preventing thalassemia in Bengal, India. Soc Sci Med 2006, 63:2661-2673.

9. Alswaidi FM, O'Brien SJ: Premarital screening programmes for haemoglobinopathies, HIV and hepatitis viruses: review and factors affecting their success. J Med Screen 2009, 16:22-28.

10. Zlotogora J: Population programs for the detection of couples at risk for severe monogenic genetic diseases. Hum Genet 2009, 126:247-253.

11. Hamamy H, Al-Hait S, Alwan A, Ajlouni K: Jordan: communities and community genetics. Community Genet 2007, 10:52-60.
12. Kaback M, Lim-Steele J, Dabholkar D, Brown D, Levy N, Zeiger K: Tay-Sachs disease-carrier screening, prenatal diagnosis, and the molecular era. An international perspective, 1970 to 1993 . The International TSD Data Collection Network. JAMA 1993, 270:2307-2315.

13. Kaback MM: Population-based genetic screening for reproductive counseling: the Tay-Sachs disease model. Eur J Pediatr 2000, 159(Suppl 3):S192-195.

14. Ekstein J, Katzenstein H: The Dor Yeshorim story: community-based carrier screening for Tay-Sachs disease. Adv Genet 2001, 44:297-310.

15. National Human Genome Research Institute: Summary of Population-based Carrier Screening for Single Gene Disorders: Lessons Learned and New Opportunities. 2008 [http://www.genome.gov/27026048\#3]

16. Bayoumi RA, Yardumian A: Genetic disease in the Arab world. BMJ 2006 , 333:819.

17. Khorasani G, Kosaryan M, Vahidshahi K, Shakeri S, Nasehi MM: Results of the national program for prevention of beta-thalassemia major in the Iranian Province of Mazandaran. Hemoglobin 2008, 32:263-271.

18. Memish ZA, Saeedi MY: Six-year outcome of the national premarital screening and genetic counseling program for sickle cell disease and beta-thalassemia in Saudi Arabia. Ann Saudi Med 2011, 31:229-235.

19. Hamamy H, Antonarakis SE, Cavalli-Sforza LL, Temtamy S, Romeo G, Kate LP, Bennett RL, Shaw A, Megarbane A, van Duijn C, Bathija H, Fokstuen S, Engel E, Zlotogora J, Dermitzakis E, Bottani A, Dahoun S, Morris MA, Arsenault S, Aglan MS, Ajaz M, Alkalamchi A, Alnageb D, Alwasiyah MK, Anwer N, Awwad R, Bonnefin M, Corry P, Gwanmesia L, Karbani GA, et al.: Consanguineous marriages, pearls and perils: Geneva International Consanguinity Workshop Report. Genet Med 2011, 13:841-847.

20. Zlotogora J, Shalev SA: The consequences of consanguinity on the rates of malformations and major medical conditions at birth and in early childhood in inbred populations. Am J Med Genet A 2010, 152A:2023-2028.

21. Bell CJ, Dinwiddie DL, Miller NA, Hateley SL, Ganusova EE, Mudge J, Langley RJ, Zhang L, Lee CC, Schilkey FD, Sheth V, Woodward JE, Peckham HE, Schroth GP, Kim RW, Kingsmore SF: Carrier testing for severe childhood recessive diseases by next-generation sequencing. Science Trans/Med 2011, 3:65ra4.

22. Watson MS L-PM, Mann MY, Rinaldo P, Howell RR: Newborn screening: toward a uniform screening panel and system. Genet Med 2006 8(Suppl 1):1S-252S.

23. Therrell B, Lorey F, Eaton R, Frazier D, Hoffman G, Boyle C, Green D, Devine O, Hannon H: Impact of Expanded Newborn Screening - United States, 2006. MMWR Morb Mortal Wkly Rep 2008, 57:1012-1015.

24. Health Resources and Services Administration: Secretary's Advisory Committee on Heritable Disorders in Newborns and Children 2011 Annual Report to Congress. Rockville, MD; 2011. [http://www.hrsa.gov]

25. al-Hosani H, Salah M, Saade D, Osman H, al-Zahid J: United Arab Emirates National Newborn Screening Programme: an evaluation 1998-2000. East Mediterr Health J 2003, 9:324-332.

26. Saadallah AA, Rashed MS: Newborn screening: experiences in the Middle East and North Africa. J Inherit Metab Dis 2007, 30:482-489.

27. National Human Genome Research Institute: DNA Sequencing Costs. Data from the NHGRI Large-Scale Genome Sequencng Program [http://www.genome.gov/images/content/cost_per_megabase.jpg]

28. GeneTests: Medical Genetics Information Resource [http://www.genetests.org]

29. Kingsmore SF, Saunders CJ: Deep sequencing of patient genomes for disease diagnosis: when will it become routine? Sci Trans/ Med 2011, 3:87ps23.

30. Kingsmore SF, Dinwiddie DL, Miller NA, Soden SE, Saunders CJ: Adopting orphans: comprehensive genetic testing of Mendelian diseases of childhood by next-generation sequencing. Expert Rev Mol Diagn 2011, 11:855-868.

31. Inati A, Zeineh N, Isma'eel H, Koussa S, Gharzuddine W, Taher A: Betathalassemia: the Lebanese experience. Clin Lab Haematol 2006, 28:217-227.

32. World Health Organization: Management of Haemoglobin Disorders [http://www.who.int/genomics/WHO-TIF_genetics_final.pdf]

33. Hamamy $\mathrm{H}$, Alwan A: Hereditary disorders in the Eastern Mediterranean region. Bull World Health Organ 1994, 72:145-154.

34. Charafeddine K, Isma'eel H, Charafeddine M, Inati A, Koussa S, Naja M, Taher A: Survival and complications of beta-thalassemia in Lebanon: a decade's experience of centralized care. Acta Haematol 2008, 120:112-116.

35. Frossard PM, Lestringant G, Girodon E, Goossens M, Dawson KP: Determination of the prevalence of cystic fibrosis in the United Arab 
Emirates by genetic carrier screening. Clin Genet 1999, 55:496-497.

36. Delea TE, Hagiwara M, Thomas SK, Baladi JF, Phatak PD, Coates TD: Outcomes, utilization, and costs among thalassemia and sickle cell disease patients receiving deferoxamine therapy in the United States. Am J Hematol 2008, 83:263-270

37. Koren A, Zalman L, Palmor H, Zamir RB, Levin C, Openheim A, Daniel-Spiegel E, Shalev S, Filon D: Sickle cell anemia in northern Israel: screening and prevention. Isr Med Assoc J 2009, 11:229-234.

38. Srinivasan BS, Evans EA, Flannick J, Patterson AS, Chang CC, Pham T, Young S, Kaushal A, Lee J, Jacobson JL, Patrizio P: A universal carrier test for the long tail of Mendelian disease. Reprod Biomed Online 2010, 21:537-551.

39. Wilson JMG, Jungner G: Principles and Practice of Screening for Disease. Geneva: World Heath Organization; Public Health Papers No. 34; 1968. [http://whqlibdoc.who.int/php/WHO_PHP_34.pdf]

40. The Human Genetics Commission.: Increasing Options, Informing Choice: A Report on Preconception Genetic Testing and Screening. London: 2011.

41. Kingsmore SF, Lindquist IE, Mudge J, Gessler DD, Beavis WD: Genome-wide association studies: progress and potential for drug discovery and development. Nat Rev Drug Discov 2008, 7:221-230.

42. Altshuler D, Daly MJ, Lander ES: Genetic mapping in human disease. Science 2008, 322:881-888

43. Ropers HH: Genetics of early onset cognitive impairment. Annu Rev Genomics Hum Genet 2010, 11:161-187.

44. Najmabadi H, Hu H, Garshasbi M, Zemojtel T, Abedini SS, Chen W, Hosseini M, Behjati F, Haas S, Jamali P, Zecha A, Mohseni M, Püttmann L, Vahid LN, Jensen C, Moheb LA, Bienek M, Larti F, Mueller I, Weissmann R, Darvish H, Wrogemann K, Hadavi V, Lipkowitz B, Esmaeeli-Nieh S, Wieczorek D, Kariminejad R, Firouzabadi SG, Cohen M, Fattahi Z, et al:: Deep sequencing reveals 50 novel genes for recessive cognitive disorders. Nature 2011, 478:57-63.

45. Firdous N: Prevention of thalassaemia and haemoglobinopathies in remote and isolated communities - the Maldives experience. Ann Hum Biol 2005, 32:131-137.
46. Farrell PM: The prevalence of cystic fibrosis in the European Union. J Cyst Fibros 2008, 7:450-453.

47. Tuncbilek E, Ozguc M: Application of medical genetics in Turkey. Turk $J$ Pediatr 2007, 49:353-359.

48. Okwi AL, Byarugaba W, Ndugwa CM, Parkes A, Ocaido M, Tumwine JK: An update on the prevalence of sickle cell trait in Eastern and Western Uganda. BMC Blood Disord 2010, 10:5

49. Kvasnicová M, Styková J, Hudec P: [Incidence of spinal muscular atrophy and Duchenne's muscular dystrophy in the juvenile population of central Slovakia]. Bratis/ Lek Listy 1994, 95:78-82.

50. Emery AE: Population frequencies of inherited neuromuscular diseases a world survey. Neuromuscul Disord 1991, 1:19-29.

51. Hantash FM, Goos DM, Crossley B, Anderson B, Zhang K, Sun W, Strom CM: FMR1 premutation carrier frequency in patients undergoing routine population-based carrier screening: insights into the prevalence of fragile $\mathrm{X}$ syndrome, fragile $\mathrm{X}$-associated tremor/ataxia syndrome, and fragile $X$-associated primary ovarian insufficiency in the United States. Genet Med 2011, 13:39-45

52. Hassan MK, Taha JY, Al-Naama LM, Widad NM, Jasim SN: Frequency of haemoglobinopathies and glucose-6-phosphate dehydrogenase deficiency in Basra. East Mediterr Health J 2003, 9:45-54.

53. Stonebraker JS, Bolton-Maggs PH, Soucie JM, Walker I, Brooker M: A study of variations in the reported haemophilia A prevalence around the world. Haemophilia 2010, 16:20-32.

54. Online Mendelian Inheritence in Man [http://www.ncbi.nlm.nih.gov/omim]

55. Hamamy H, Bittles AH: Genetic clinics in Arab communities: meeting individual, family and community needs. Public Health Genomics 2009, 12:30-40.

\section{doi:10.1186/gm324}

Cite this article as: Kingsmore SF, et al.: Next-generation community genetics for low- and middle-income countries. Genome Medicine 2012, 4:25. 